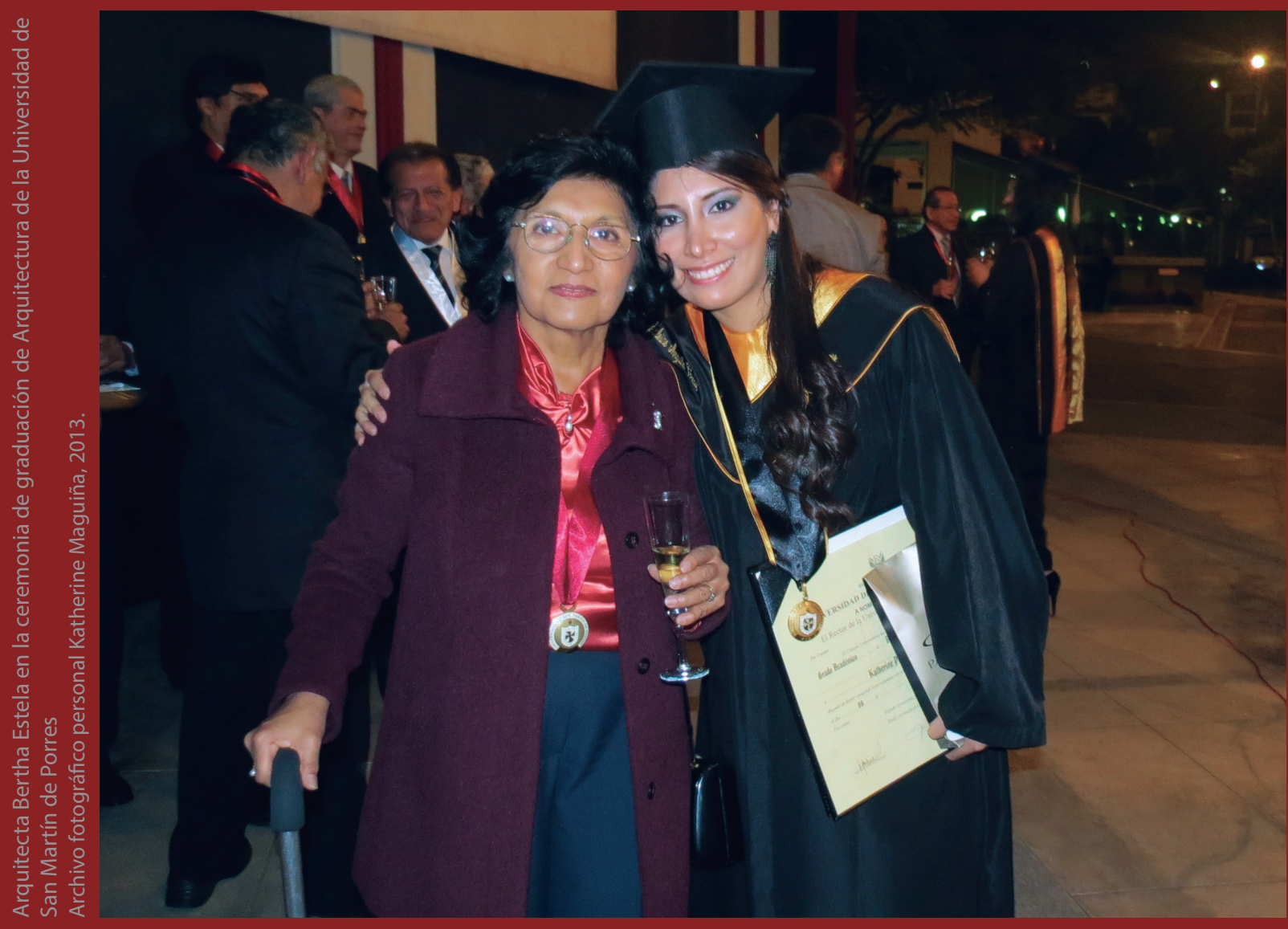

\title{
Entrevista Bertha Estela Benavides
}

Arquitecta por la Universidad Nacional de Ingeniería del Perú. Premio Nacional Fomento de la Cultura -mención honrosa- por tesis universitaria, otorgado por el Instituto Nacional de Cultura (INC) en 1971. Posgrados en el curso Restauración de Monumentos del PNUD/UNESCO/INC, en Cusco-Perú (1975) y en el curso Conservación Arquitectónica del ICCROM en Roma-Italia (1979). Ha ejercido el cargo de directora nacional de Patrimonio Monumental e Histórico en el INC (1986-1989; 1999-2003). Es miembro del Consejo Ejecutivo del Centro Internacional de Estudios para la Conservación y la Restauración de los Bienes Culturales (ICCROM) de Roma, en representación del Perú (2001-2005). Ha realizado supervisión, proyectos y obras de restauración para el Estado peruano y para entidades privadas, en Lima, Cusco, Áncash, Trujillo, Cajamarca, Huancavelica y otros. Entre sus principales obras destacan la Quinta y Molino de Presa (Lima), el Convento de San Agustín (Lima) y la Iglesia de la Compañía de Jesús (Ayacucho). Actualmente, es docente e investigadora de la Facultad de Ingeniería y Arquitectura de la Universidad San Martín de Porres. 
Extracto de la entrevista realizada el 24 de febrero de 2016 por el Sr. Christian García Barba, el Sr. Rodrigo Ramírez Vides y la Srta. Daphne Valdivia. Lima, Perú.

CG: Arquitecta, buenos días. Antes de conversar sobre su recorrido profesional, nos gustaría saber si hubo algún evento durante su educación primaria o secundaria que la motivara de forma significativa a estudiar Arquitectura.

BE: Yo creo que sí hubo un evento muy impactante en mi vida. Vivía yo desde muy pequeña en Cañete, y cuando tenía dos o tres años ocurrió algo que recuerdo muy bien: hubo un terremoto en 1948; entonces yo vivía en una casa que se encontraba en una esquina y recuerdo que la iglesia de la localidad sufrió grandes daños: finalmente decidieron las autoridades que era necesario tumbar dicha torre. Recuerdo eso con gran detalle porque yo la veía desde la esquina de mi casa; por ello ha quedado marcado en mí como lo que más recuerdo. Quizás este acontecimiento fue algo determinante para mí... Ya después, siempre me interesó la Arquitectura pero dentro de la formación universitaria no se toma en cuenta la restauración de monumentos. Solo cuando llevé cursos con el arquitecto Emilio Harth-Terré, quien nos concientizó sobre todo el bagaje histórico y sin estudiar que tenemos en nuestro país. Él tenía fichados 14 mil artífices, entre arquitectos, alarifes, etc. Y, bueno, eso motivó también la elección del tema de mi tesis de bachillerato.

CG: Nos está mencionando que el arquitecto Emilio Harth-Terré fue uno de los personajes que más la influenciaron. ¿Este legado o herencia se refleja también en su labor profesional?

Sí, en lo que es restauración de monumentos, sobre todo, y por ello siempre trato de impartir esa misma motivación a mis alumnos. Siempre intento expresarme con justicia sobre el arquitecto Harth-Terré, porque mucha gente siempre habla del "Harth-terrorismo" y muchas otras cosas, pero uno tiene que juzgar a las personas considerando el contexto en el que trabajaron: cuando él trabajaba no existía la Carta de Venecia, ni mayor normativa. Por ejemplo, el desconocimiento de estos temas de restauración monumental cuando sucedió el terremoto de 1940 hizo que muchas personas decidieran demoler. Nunca fue su decisión, sino más bien fue una cuestión política, y el arquitecto Harth-Terré hizo lo mejor que pudo. Muchas cosas de las que existen hoy en día son resultado de su intervención, de su investigación. Su trabajo fue una verdadera labor de vocación y eso es lo que hay que rescatar.

RR: ¿Siente ese mismo legado por parte de otros arquitectos?

Sí, por varios... Muchos han influido, sobre todo mis profesores de Historia, entre ellos los arquitectos José García Bryce, Frederick Cooper, José De Mesa.

RR: Trabajar en el INC le brindó muchas oportunidades para participar en proyectos de restauración de monumentos. ¿Estas experiencias le hicieron cambiar su forma de pensar con respecto a su formación académica, o se reforzó lo aprendido de alguna manera?

Sí, se reforzó. Los cursos de posgrado también te enriquecen... por ejemplo, los criterios que utilizó el arquitecto Harth-Terré, quien nos explicó de propia voz por qué criticaban tanto lo que él había hecho. Además, la tecnología va avanzando... siempre sigue progresando y uno tiene que estar al día con los avances. Incluso lo que yo he aprendido en el ICCROM ya ha sido sobrepasado, como el tratamiento de las pátinas.

DV: ¿Cuál fue el proyecto más significativo que usted desarrolló en su primer periodo en el INC?

Me acuerdo mucho de la primera obra, mi primer proyecto, pero luego se han hecho cosas muy importantes. Tuve la suerte de trabajar en una muy buena época, cuando la directora del INC era la Dra. Martha Hildebrandt, quien estaba bien acompañada por los consiguientes primeros directores. Existía un ambiente laboral de respeto. Se contaba con una buena infraestructura, siempre con un buen clima de trabajo y con los mejores profesionales trabajando ahí. Había mucha mística, mucho movimiento, bastante apoyo a nuestras labores. 
DV: Hablando de las personas que la rodeaban en esa época, usted pertenece a una generación de profesionales que se comprometieron mucho con el patrimonio histórico. ¿Siente, quizás, que ese compromiso ha menguado, o se ha intensificado?

No me parece que haya menguado. Yo creo que siempre hay personas que se interesan porque se les educa bien. Por ejemplo, actualmente en la Escuela de Arquitectura de una universidad limeña soy responsable de un curso electivo en el cual siempre tengo una gran cantidad de alumnos matriculados. Ellos están siempre súper interesados, y hacen las prácticas y el trabajo de campo con gran motivación, y esa es una de mis labores. Yo pienso que lo que en realidad hace falta es motivar bastante a los chicos desde el colegio. Creo que se tendría que invertir mejor en la educación... en la calidad de los textos escolares. Yo creo que si existiese dicha motivación y se aprendiese el respeto, por lo menos... Por ejemplo, yo creo que algo seguro es que todos los estudiantes de Arquitectura en su ejercicio profesional van a trabajar alguna vez en centros históricos; en buena hora, que se hagan intervenciones modernas que ayuden a revitalizar los centros históricos, pero siempre respetando su contexto... porque, al final, ¿qué es la arquitectura? La arquitectura es el resultado de una sociedad, de todos los conocimientos tecnológicos, científicos, hasta la cuestión espiritual... todo. Es el ser humano que se refleja integralmente en la arquitectura.

CG: ¿Cuándo y por qué deja de trabajar en el INC? ¿Qué actividades empieza a realizar a partir de ese momento?

Yo dejé el INC dos veces, y en ambas oportunidades fue por defender el patrimonio. Porque, si ese el deber que yo tengo, entonces no voy a ceder ante la presión de "que me quiten la multa". Es así cuando se trabaja con el Estado, y bueno... Yo siempre he realizado obra nueva, siempre he proyectado... Eso sí, cuando estuve en el INC nunca hice proyectos de restauración particulares por cuestiones de ética profesional. El Estado peruano me pagaba para que yo realizara proyectos de restauración para quien lo necesitara.

CG: Usted mencionó que durante la dictadura del general Juan Velasco se realizó un gran aporte al rescate y puesta en valor del patrimonio, ¿es cierto?

Claro, es que el INC fue fundado en ese momento, al igual que el Decreto Ley 19033; ambos representaban oportunidades interesantes y recientes. En ese mismo periodo de gobierno, como un gran acierto, también se nombró como directora del INC a la Dra. Martha Hildebrandt y, además, se buscó reclutar a los mejores profesionales en diversos campos de la cultura. Existía el apoyo y no había injerencia política.

RR: ¿Cómo examina la evolución de las leyes y normativas que se han promulgado sobre los temas del patrimonio?

Mira, la siguiente ley (Ley General de amparo al Patrimonio Cultural de la Nación № 24047) se gestó ya en el gobierno del arquitecto Fernando Belaúnde, y considero que fue contraproducente. Te explico: dicha ley llegó al INC para que emitiéramos opinión mediante respectivos informes (técnico y legal) con relación al texto de dicha ley. Ambos informes estaban en contra, porque considerábamos que le quitaba al patrimonio las tres "ies" (intangible, inalienable, imprescriptible). Ello debe tenerse siempre en cuenta porque no se cuenta con historia escrita de todo, y cada evidencia que se encuentra es una página de nuestra historia... y eso fue lo que le quitaron. Entonces, ¿qué pedían? Que todo bien, para que fuera considerado Patrimonio Cultural de la Nación tenía que estar inventariado. Y eso es imposible, porque inventariar todo el patrimonio, pues, es imposible; necesitaríamos todo el presupuesto de la nación para hacerlo. Se ha subsanado en algo después, pero la ley existente es muy basta. La ley para el patrimonio debería ser más concisa, porque mientras más basta es tiene más espacio para que los abogados hagan de las suyas... 
DV: Hace un momento mencionaba algunas críticas que recibió el arquitecto Harth-Terré por sus intervenciones en el centro histórico, principalmente por parte de la Agrupación Espacio. ¿Puede explicarnos mejor a qué se refiere?

Pues yo no sé si esas críticas eran de parte de la Agrupación Espacio en sí misma, puesto que muchos de ellos también fueron mis profesores, pero creo que ya no se hacían llamar Agrupación Espacio entre 1966 y 1969. Pero era en general, la crítica era por realizar una arquitectura neocolonial en la cual las proporciones habían variado. Eso es lo que yo oía de muchos arquitectos a quienes también yo estimo mucho. Es cierto que se hacen cosas malas con buenas intenciones, pero no existía la reglamentación en ese momento; es decir, no le podemos exigir algo que no era parte de su contexto. Ahora, si hoy en día se realiza algo pensando que está bien pero por ignorancia de la ley, entonces sí les debe caer todo el peso de la ley, porque un profesional debe saber la reglamentación. En esa época no había esas cosas... Yo creo que él hizo lo mejor que pudo... pero en cuanto a estudios, investigación, ha desarrollado muchas cosas muy valiosas, incluso lenguaje mochica.

DV: Hablando de la modernidad, hoy vemos a la ciudad de Lima expandirse y encerrar los restos prehispánicos. ¿Cuál es su opinión al respecto?

Mira,... los cambios modernizadores ocurrieron en Lima cuando ya existía el aval que representaba la Carta de Atenas (1933), desgraciadamente. Eso se generó no solo acá, si no en todas partes del mundo, aunque mientras más culto era un pueblo más se lograba impedir y frenar eso. Por ejemplo, en París nunca se llegó a realizar el proyecto de Le Corbusier, y en Alemania han reconstruido las fachadas de sus monumentos con mayor identidad histórica. En ese escenario histórico y mundializado es que empezamos a seguir localmente los preceptos de dicha Carta de Atenas y luego de la Carta de Venecia. Se hicieron excelentes edificios, pero que estaban totalmente fuera de contexto, como el edificio Atlas de Walter Weberhofer, quien además es un excelente arquitecto. También se edificó un hotel del arquitecto Mario Bianco, hermosísimo pero igualmente fuera de contexto. El edificio de seguros de la Compañía Peruano-Suiza también es un excelente edificio, fuera de contexto. El otro asunto son las ampliaciones de la ciudad. En este tema sí creo que metió la pata el general Velasco, porque en ese momento esas cosas ya no se debieron haber hecho. Destruyó el espacio urbano de las iglesias...

CG: Nos mencionó que también enseñó en una maestría en la Universidad Nacional Federico Villareal...

Sí, de 1986 a 1988, cuando estuvo a cargo de un profesor arquitecto de origen ruso, Waldemar Moser, quien se interesó muchísimo por la historia del Perú. El problema con las maestrías en el Perú es que en general son muy teóricas... bueno, deben ser teóricas, pero también deberían tener un componente mayor de prácticas, como los cursos que se dictan en el ICCROM.

CG: Arquitecta Estela, la restauración de algunos monumentos prehispánicos en Lima, como la huaca Pucllana de Miraflores, un caso de privatización, ¿qué opinión le merece?

Yo creo que eso no es privatización, y para estas cosas no hay que ser más papistas que el papa. Cuando se comenzó a trabajar yo estuve ahí con la doctora Isabel Flores, quien sigue siendo la directora del proyecto, y es excelente. Fue precisamente ella quien realizó un proyecto integral, incluso con la participación de la Universidad Cayetano Heredia, con un gran equipo de profesionales... Como se debe realizar una exploración arqueológica, con ingenieros, arqueólogos, historiadores, arquitectos, etc. El propietario es la Municipalidad Distrital de Miraflores, una municipalidad que tiene los recursos y los utiliza, y el restaurante sirve para sufragar esos gastos. Pero eso es una parte mínima de todo el complejo ceremonial, porque todo el resto fue urbanizado. Ahí se ha descubierto que los sacerdotes eran mujeres; o sea, existían sacerdotisas. Sabemos esto gracias a la restauración científica que se ha hecho. Ahora, creo yo que no se pueda entregar totalmente en uso, tampoco en concesión privada, porque lo destruyen inmediatamente... 
RR: Arquitecta, esta entrevista será expuesta a la opinión pública. ¿Qué mensaje le daría a los jóvenes que se están empezando a interesar en la conservación del patrimonio?

Pues, creo que lo más valioso que les podría decir es que la esencia de la mirada patrimonial es el respeto; respeto a la historia, a tu contexto, a lo que te rodea. No importa dónde y cuándo vayas a diseñar; si no tomas en cuenta el contexto y el respeto hacia este, entonces estás mal. El respeto es lo que genera buenos proyectos en los centros históricos. Por ejemplo, la Plaza San Marcos en Venecia se construyó a lo largo de 200 años: no son edificios de la misma época ni de los mismos estilos; sin embargo, existe armonía en el conjunto ¿Por qué? Porque existe un gran respeto por lo que otros hacen, por el legado, por la historia... 